\title{
La teología negativa. Nuevas teorías
}

Un tema ambiguo planteado por san Agustin y Suárez.

La obra de Josef Hochstaffl ${ }^{1}$ alude a un aspecto del tema de la existencia de Dios que resulta pavoroso para el descreído y abrumador para los creyentes distraídos, que no toman en serio la religión. En ambos casos produce consternación el pensamiento de Dios, por lo mucho que de él sabemos y por lo mucho que ignoramos de su naturaleza y de sus atributos. Es infinito lo que de Dios sabemos e infinito lo que ignoramos todos. Es obvio que la mente desprovista de las vivencias de la fe, colocada al borde de ese doble abismo insondable, sienta pavor y consternación. No tiene más alternativa que entregarse a los designios divinos o rechazarlos con la fuga de Dios, mediante la negación de su existencia. Es una situación dramática que recuerda la escena del paraíso, cuando Adán, acostumbrado antes a la suave y luminosa conversación divina, al verse en pecado huye a la oscuridad de la selva, junto con Eva, aterrados ambos de la presencia divina.

No siempre el alejamiento de Dios produce un sentimiento tan trágico de consternación. Ni la Teología negativa " adquiere los rasgos de alienación religiosa alocada o un ateísmo sistemático. Sin volver a Dios la espalda en forma descarada, puede disimularse el misterio con motivos multiformes, doctrinales unos y prácticos otros, con distracciones más o menos justificables o con discusiones filosóficas o teológicas de críticos eminentes que en formas variadísimas plantean el problema, hoy muy estudiado, de la TN como lo hace Hochstaffl en la obra a que nos referimos antes.

El título escueto de la obra no es sin embargo una novedad extraordinaria. El tema resulta inquietante o atractivo en su subtí-

1. Josef Hochstaffl, Negative Theologie. Ein Versuch zur Vermittlung des patristischen Begriffs (München, Kösel Verlag, 1976) 272 pp.

2. En adelante empleamos las siglas $T N$ para indicar la Teología negativa. 
tulo: Teología negativa: un intento de conciliación del concepto patrístico. Pero, conciliación ¿con quiénes? El índice bibliográfico enumera más de mil títulos de libros y artículos relativos a la afirmación y negación de Dios. El autor ha descrito la espesa frondosidad conceptual de ambos términos a lo largo de la historia; y al final de la obra dedica importantes capítulos a los prolegómenos lingüísticos y hermenéuticos necesarios para llegar a una conciliación que - con criterios de especialista en Teología pastoral, en la Falcultad teológica de Paderborn, y conforme al espíritu del Vaticano II-, cree suficiente para dar a la $T N$ una figuración o precisión especial aceptable para el hombre moderno ${ }^{3}$.

En la exposición del tema se aduce un material denso y amplisimo de elementos históricos de filosofía y teología conceptual, con el fin de hacer consciente al lector acerca de la evolución de los elementos afirmativos y negativos de la terminología relativa a Dios, en las diversas religiones y escuelas que han tratado sobre el tema. Es obvio que en la exposición de un tema amplio haya lagunas de más o menos importancia. Entre ellas nos es preciso señalar omisiones que creemos esenciales, como son las doctrinas del estoicismo precristiano heredadas por el cristianismo, y las posiciones últimas de la época postridentina en el concepto del Verbo o de la Palabra con aplicaciones filosófico-teológicas, especialmente en Suárez. La omisión de la doctrina estoica sobre el Verbo la consideramos importante, porque la filosofía cristiana de los Padres, y entre ellos el Ps. Dionisio en su teoría sobre la Teología apophática, depende más del estoicismo que de la filosofía de Aristóteles y Platón.

La omisión del pensamiento escolástico postridentino -especialmente el de Suárez- es particularmente sensible, una vez que el autor ha dado importancia tan decisiva al pensamiento alemán que sigue una orientación diversa a la de Suárez, a pesar del conocimiento que los grandes filósofos germanos han tenido del filósofo y teólogo español, cuya doctrina lingüística ha precedido a los trabajos más logrados de los teólogos actuales posteriores al Vaticano II.

En el pensamiento suareciano hay que distinguir varios esquemas lingüísticos:

a) El lenguaje sistemático humano y racional, utilizable tanto por los hombres como por seres superiores y por el mismo Dios;

3. Cf. p. 235. De no precisar otra cosa, nos referimos siempre a la obra de Hochstaffl, que hemos indicado en la nota 1. 
b) Lenguaje no sistemático que sirve para comunicarse entre sí los hombres y seres racionales superiores, e incluso el mismo Dios, en forma no sistemática ni propiamente racional.

c) Lenguaje propiamente divino, natural o sobrenatural, utilizable sólo por Dios.

El tema de la inefabilidad divina y el de la $T N$ se pueden presentar en los tres esquemas lingüísticos que denominaremos: ahumano, suprahumano o no-sistemático y divino. La mente humana no puede saber en los dos últimos esquemas si una propiedad divina es o no inefable, pues desconoce las posibilidades lingüísticas o comunicativas de estos esquemas. Por eso Suárez lo plantea en el primero, diciendo:

"Ante todo, se debe decir que Dios es y se dice inefable verdadera y propiamente. La dificultad está en el modo de entender este atributo, pues no podemos decir de modo absoluto que Dios es inefable, ya que no hay nada más frecuente en nuestra conversación. Tampoco le podemos llamar indenominable, ya que le designamos con tantas denominaciones. De ahí que con su agudeza habitual, Agustín no parece consentirnos llamar a Dios inefable para evitar las contradicciones de este término ${ }^{4}$. Pues habiendo dicho algunas cosas de Dios, pregunta: ¿Hemos dicho algo? ¿Resonó en nosotros algo digno de Dios? Si dije algo de la Trinidad, no es eso lo que quise decir. ¿Cómo lo sé, sino porque es inefable? Ahora bien, lo que dije, si es inefable, no lo habría dicho. $Y$ añade: ' $Y$ según eso, ni siquiera se ha de llamar inefable a Dios, porque al decir esto se dice y resulta no sé qué altercado de palabras, porque si es inefable (=cosa que no es decible) no es inefable, haciendo lo inefable algo que se puede decir. Este altercado de palabras, dice Agustín a continuación, se debe aplacar más con el silencio que con voces. Sin embargo, nos tenemos que esforzar con todos los teólogos para explicar cómo se llama a Dios inefable" 5 .

Si bien se observa, Suárez no plantea el problema del mismo modo que en la cita agustiniana. Agustín ha hablado en el capítulo precedente del De doctrina christiana, de la Trinidad y unidad de Dios, dogma sólo conocido por la revelación divína, que ha de ser aceptado por el creyente como enunciado por Dios en el esquema lingüístico divino, que hemos explicado más arriba. El hombre se limita a repetir lo que Dios dice empleando sonidos de lenguaje humano vulgar, cuya significación última contiene una verdad aceptada por el creyente, pero no inteligible por su razón, en cuanto al

4. De doctr. christ. I 6 PL 34, 21.

5. De Deo uno I 31, 3: vol. I 182 
contenido profundo y real del dogma, entendiendo las palabras pero sin comprender su cohesión interna. En cambio, Suárez dice que el atributo de la inefabilidad expresado en el lenguaje sistemáticamente racional humano no es contradictorio por tratarse de planos lingüísticos diversos. Es lo que ocurre, por ejemplo, cuando decimos que no podemos expresar con palabras algo que estamos comunicando con la risa o con el gesto. El altercado de las palabras sólo se produce cuando éstas se sitúan en el mismo plano afirmando y negando una misma cosa.

Suárez expone así su pensamiento: "Hay que suponer en primer lugar que Dios se dice inefable con voz humana, en conversación y palabras o nombres pronunciados con la boca, porque en orden a los conceptos o palabras mentales, Dios se dice incomprensible o invisible, como veremos. Por tanto, nada hablaremos aquí del modo con que los ángeles pueden tratar de Dios, pues según creemos no hablan signos convencionales significativos, correspondientes a nuestros conceptos o voces, sino manifestando sus conceptos. Por lo cual lo mismo vale de su lenguaje y concepción o conocimiento, porque el lenguaje sólo añade la voluntad de presentar a otro objetivamente el concepto propio, para que él lo vea. Por la misma razón no tratamos de los que poseen la visión de Dios. Pues si ellos pueden hablar de Dios en cuanto visto por ellos, no hablarán al modo humano, sino al modo angélico o mejor al modo divino, manifestando los conceptos en ellos mismos. Según lo cual, se trata de voces humanas, que tienen su fuerza en la significación porque sólo en virtud de ella sirven para el lenguaje, en cuanto las voces son signos de los conceptos, como dijo Aristóteles. Ahora bien, esta significación de las voces y de los nombres no es natural sino de cada uno que tenga autoridad para dársela con imposición divina o humana" 6 .

Con su habitual perspicacia insiste Suárez en la descripción del lenguaje racional humano, descubriendo en él las características siguientes: 1) el sujeto emisor de la palabra y su destinatario o interlocutor; 2) la función expresiva de conocimientos o sentimientos y la recepción de los mismos en el destinatario; 3) el objeto conocido por el sujeto emisor, que ha de ser también conocido por el interlocutor o destinatario; 4) los signos convencionales o palabras, como puente de unión que conecta a los interlocutores; 5) referencia unívoca o igual en ambos interlocutores al objeto del diálogo; 6) contacto comunicativo interpersonal de los interlocutores; 7) mensa-

6. Ibid. I 31,5 . 
je poético elaborado por el emisor con creación estética, destinada a influir en el destinatario.

En la terminología metalingüística moderna se habla de códigos de signos y de la función fática del lenguaje, como puede verse en B. Quelquejeu ${ }^{7}$ que se inspira en $R$. Jakobson ${ }^{8}$. Con terminología menos elaborada y más usual se pueden ver en Suárez esas mismas categorias en los pasajes citados y en este otro:

"De lo cual se puede entender que todo nombre procede de conocimiento y tiende al conocimiento. Porque significando por convención supone el que lo impone el conocimiento de aquello que se trata de significar al imponer el nombre, pues es imposible hablar de cosas desconocidas, y es mucho más imposible que uno ponga nombre a lo que desconoce del todo. Por eso nos dice el libro del Génesis 2,19 que trajo Dios los animales a Adán para que viera cómo los habría de nombrar pues sin previo conocimiento no les podia poner nombres. El hombre se ordena a producir el conocimiento de la cosa por él significada en la mente del oyente, pues todos los signos sensibles se ordenan a ese fin, ya que es propio del signo sensible que, además de la especie introducida en los sentidos, haga que otra cosa venga a ser conocida, como dice Agustín $^{9}$, y es común entre los escolásticos. Consecuentemente las voces humanas tienen la propiedad de ser instrumentos, con los cuales pueden manifestar sus conceptos y sentimientos, como dijo Aristóteles ${ }^{10}$, y directamente mueven al conocimiento de las cosas significadas inmediatamente. Estas cosas a veces pueden ser cosas externas, como un hombre o un león, y a veces los conocimientos mismos, si los hombres le han puesto para significarlos, como es esta misma palabra conocimiento, o el verbo pienso, o el nombre intelección u otros semejantes. Con todo, los nombres no significan las cosas más que en cuanto se presentan a los conceptos de los interlocutores, y poniéndolas a las mentes de los interlocutores. $Y$ asi sirven para manifestar y expresar los propios conceptos, ya que al no poder manifestar a otro nuestros conceptos en sí mismos, nos serviremos de palabras para manifestarlos. De donde se puede entender una cosa muy necesaria, es decir que los nombres de las cosas por su virtud no engendran en nosotros un conocimiento intuitivo de la cosa significada, sino sólo un conocimiento abstractivo. Por eso aunque el que habla o pone el nombre significativo tenga conocimiento intuitivo de la cosa significada o que debe significar, con todo, el nombre en virtud de su misma imposición no puede re-

7. "El problema escribir. Algunas preguntas a los que escriben teologia", Concilium 1976, pp. 219-232.

8. Essais de linguistique générale (Paris 1963) cap. 11.

9. De doctr. christ. II al comienzo.

10. De interpretatione. 
presentar intuitivamente la cosa significada. Por lo cual la visión del que pone el signo o lo utiliza al hablar es cosa accidental, pues el nombre no significa para el que habla o pone, en cuanto tales, sino para los oyentes en cuanto tales. $Y$ este es el fin intrínseco y connatural de tales signos" 11.

Estableciendo los principios lingüísticos relativos al esquema humano y racional de la teología, en contraposición a los otros dos esquemas, resulta evidente la posibilidad y aún la necesidad de hablar del atributo de la inefabilidad divina. Suárez lo prueba partiendo del supuesto de nuestra posibilidad de hablar de muchas de las propiedades de cosas inadecuadamente conocidas por desconocer su naturaleza quiditativa o esencial envuelta en otras manifestaciones de la misma. Es decir, sabemos y decimos muchas cosas de Dios, aun cuanđo su esencia íntima sea incomprensible e invisible a la mente humana. He aquí el raciocinio de Suárez:

"Suponiendo esto, digo en segundo lugar: No hay nombre de Dios que le signifique o represente quidditativamente o esencialmente. Por esto, se le llama con razón inefable, y en ese mismo sentido se le puede llamar innombrable, o indenominable, aunque esta palabra no sea usual. Así lo dice santo Tomás ${ }^{12}$, con él otros teólogos que citaré a continuación. Lo mismo sienten Dionisio, Cirilo, el Nacianceno y Agustín, a quien cité al principio" ${ }^{13}$.

El atributo de la inefabilidad lingüística puede proceder no sólo de la incomprensibilidad de la esencia divina, sino también de otras causas. Hay conocimientos más o menos perfectos que no acertamos a formular con nuestro código lingüístico. Por eso nuestra incapacidad de hablar de Dios no lleva consigo la incapacidad de conocerle en sus propiedades inefables. Puede haber sujetos que viven una religiosidad profunda que desborda las facultades expresivas de sus vivencias y conocimientos. Esto ocurre normalmente con los místicos, como san Pablo, san Juan, san Ignacio, santa Teresa, y otros muchos. Incluso teólogos, que no figuran como místicos, experimentan vivencias luminosas difícilmente enunciables o sencillamente inexplicables en exposiciones doctrinales. Es lo que actualmente se llama "teología como biografía", según puede verse en un artículo de J. B. Metz, hablando del P. Rahrier ${ }^{14}$.

Este conocimiento supralingüístico de los misterios inefables de Dios es una posibilidad que Suárez describe profusamente como

11. Suárez, De Deo uno I 5-8.

12. Ibid.

13. Suárez añade otros pasajes del Damasceno, Gregorio Magno, Justino, Origenes. y Eph. 1, 20, Prov. 30, 4 y Gn 32, 29.

14. Cfr. "Teología como biografía. Una tesis y un paradigma", Concilium 1976, pp. 209-218. 
realizable, no sólo en Dios, sino en los ángeles y en los hombres, lo mismo en la visión escatológica del cielo como en diversas hipótesis de situaciones humanas en este mundo. De este modo responde a las objeciones escolásticas formuladas contra el dogma de la inefabilidad, partiendo del principio de que nuestro código humano de signos lingüísticos nos remite, por la misma naturaleza convencional de la lengua entendida dentro del ancho campo de la evolución lingüística, a la objetivación idéntica concreta y fija en cada caso para interlocutores, quienes quiera que sean, sin excluir el diálogo de Dios con los hombres. Siempre resultará que los interlocutores, para hablar, se habrán de referir a una cosa idéntıca igualmente representada en su objetividad en la mente, aunque las vivencias subjetivas de los interlocutores sean de una variedad infinita.

La inefabilidad divina es, según esto, una parte o aspecto de la fe corporativa obligatoria e idéntica reflejada igualmente por todos los creyentes, sin perjuicio de las diversidades vivenciales pluralistas, más o menos perfectas, que acompañan a la fe común en cada uno de los fieles. Esta objetividad univoca y real se verifica en el proceso de la objetivación cognoscitiva, base del lenguaje comunicativo de ideas idénticas, sin cuya absoluta identidad careceria de sentido el tema de la conversación y el intercambio social de la vida y de la cultura. Es un tema profundamente estudiado por Suárez, al margen de todo subjetivismo idealista, antes de Kant, como puede verse en un trabajo que publicamos hace años ${ }^{15}$.

Conviene, pues, dejar bien claro que sólo en esa franja de la comunicación língüística objetiva tiene sentido el atributo de inefabilidad divina. El propio san Agustín reduce a este campo el "altercado" de la inefabilidad: "Porque en verdad no se conoce a Dios en el ruido - strepitu - de las sílabas. Sin embargo, a todos los conocedores de la lengua latina, cuando llega a sus oídos este sonido, les mueve a pensar en una naturaleza excelentísima y universal" ${ }^{16}$.

La contraposición entre el estrépito de las sílabas y el conocimiento del ser excelentísimo pertenece a la filosofía estoica del Verbo, no al lenguaje convencional humano de la filosofía aristotélica, donde se produce el altercado sobre la inefabilidad. Para el Verbo estoico o para el Verbo del prólogo de san Juan no tiene sentido la inefabilidad, como puede verse en el pasaje conocido de

\footnotetext{
15. "El concepto objetivo en Suárez", Pensamiento 1948, pp. 334-423, completado por "La acción de resultancia en Suárez", Anales Francisco Suárez, Universidad de Granada, 1943, pp. 45-96.

16. De doctr. christ. I, 7 PL 34, 21.
} 
Séneca acerca de Júpiter: "cuando sin los otros dioses y evaporado el mundo, se halla solo con sus pensamientos" ${ }^{17}$. En este lenguaje o metalenguaje no tiene sentido la inefabilidad ni para Séneca, ni para san Agustin, ni para Suárez ni para cualquier otro pensador. La $T N$ queda excluida de este campo superior. La franja de la inefabilidad, según Suárez, presupone otra zona inferior y previa al lenguaje teológico normal de la $T N$, propia de la fe responsable del hombre social y adulto. Suárez describe esa zona preliminar cuando escribe, distinguiendo dos capítulos por los que se origina el conocimiento de Dios en nuestra mente:

"Así, pues, de dos capitulos pudo brotar esta noticia de la existencia de Dios. Primero, por la máxima proporción que esta verdad tiene con la naturaleza humana, pues enunciada esta verdad y explicados los términos, aunque no aparece como del todo evidente, sin embargo, aparece tan acomodado por sí mismo a la razón, que fácilmente se persuade de ella el hombre que no está completamente depravado" 18.

Hay, según esto, un metalenguaje correspondiente al Verbo creador de la naturaleza cósmica y humana, que desborda el lenguaje humano convencional, tanto en su fase incoativa explicada por Suárez ${ }^{19}$ como en la transformación progresiva de la imagen de Dios en el hombre hasta llegar a la visión intuitiva de la esencia divina en la gloria. Son zonas en las cuales el Verbo creador de san Juan, filosóficamente preelaborado en la cultura aramea, sistematizado por el estoicismo y elevado al orden sobrenatural en la Revelación, resulta ajeno al convencionalismo lingüístico griego y aristotélico, dentro del cual tiene sentido la $T N$ y la inefabilidad.

Suárez, comentando a san Juan, defiende que Cristo es con toda verdad y propiedad la Palabra o el Verbo del Padre, observando agudamente, contra la traducción erasmiana de sermo en vez de Verbum, que el sermo es la oración compuesta de partes, mientras que el Verbum es algo simple. Por eso deduce que es más correcto llamar Verbo al Hijo de Dios, en cuanto tal, y Sermo a Cristo, Dios y hombre, es decir persona composita, como también le llama santo Tomás, por las relaciones teándricas que le ponen en diálogo con la humanidad ${ }^{20}$. Las propiedades de este lenguaje o metalenguaje, propio de la Escritura, de la tradición patrística y de los teólogos, ha sído objeto de un estudio profundo ${ }^{21}$.

\footnotetext{
17. Séneca, Epist. 9, 16 .

18. Suárez, $D M 29,3,36 ; 26,60$.

19. Ibid.

20. Suárez, De Trinitate IX 2, 6, 7, vol. I 724

21. "Las leyes de la Palabra $y$ sus aplicaciones exegéticas, según Suárez", Miscelánea Comillas 41 (1964) separata pp. 34.
} 
En el problema de la $T N$, esbozado ya en san Agustín y en Suárez, hay acuerdo fundamental, sin divergencias notables entre los autores escolásticos, incluido santo Tomás. Si nos hemos fijado en san Agustín y Suárez es por la importancia dada por ellos al aspecto lingüístico, lo mismo que en las teorias recientes sobre la $T N, y$ por la atención prestada a la doctrina estoico-aramea sobre el Verbo en un sentido sobrenaturalizado por la Escritura y especialmente por san Juan. De este aspecto dinámico - eficiente del Verbodesconocido para Platón y Aristóteles, no se puede prescindir en la teoría sobre la $T N$. Sólo a su luz podemos contrastar las novedades introducidas en la dirección evolutiva de la $T N$, que debemos exponer con la mayor objetividad posible en un sumario, que ofrecemos sin intercalar juicios críticos nuestros. Nuestras observaciones irán en notas marginales. Recurriremos en pasajes más importantes al entrecomillado, con el procedimiento de hablar en nombre del autor.

\section{Conato conciliador del concepto patrístico}

Vamos a exponer, con el criterio pastoralista del Vaticano II, la doctrina de la $T N$ dándole un giro acomodado a la mentalidad del hombre moderno. "De Dios no conocemos lo que es, sino lo que no es, como puede verse en santo Tomás" ${ }^{22}$. ¿Cómo pasar de esta negación básica al conocimiento positivo de Dios? Hay diversos conceptos de TN que permiten soslayar estas dificultades y evitar el peligro de la idolatría, aunque tales conceptos tienen el riesgo del subjetivismo. Es preciso pensar cómo la TN puede posibilitar la promoción de una libertad en la historia, considerando la historia como algo que acabará de plenificarse en sí. Demostraremos que esto es posible a base de un postulado de la dialéctica negativa, haciendo ver cómo la $T N$ y la dialéctica negativa se esclarecen mutuamente en una crisis práctica, utilizando las estructuras teológicas de la $T N$ para las creencias dogmáticas ${ }^{23}$.

La $T N$ es noción introducida a finales del siglo $\mathrm{V}$ por el Areopagita, con el nombre de apophasis o negación, contrapuesto a kataphasis o afirmación. Sinónimos de apophasis son stéresis (privación), aphairesis (abstracción), apagoreuo (prohibir) y arêomai (negar). Dionisio llama con frecuencia theologias, en plural, y thesis, a las afirmaciones. "En este concepto aparece la distinción de tres momentos, uno positivo, otro negativo y la afirmación. Sin duda Dionisio no ha distinguido entre teologia negativa, en cuanto forma bá-

22 Santo Tomás, S. Th. I 3.

23. Cfr. pp. 11-12. 
sica teórica para toda teología y la $T N$, o proposiciones negativas sobre Dios, como aplicaciones metódicas" ${ }^{24}$. En los padres la distinción areopagítica no es tan clara, pero inducen a una investigación histórica más profunda.

Los orígenes de $T N$ están en la oposición de la Biblia a toda soteriologia natural. El tema de la inconformidad -Unverfügbarkeit, indisponibilidad- divina se ha tratado con frecuencia en la teología bíblica como un antropomorfismo del A. Testamento ${ }^{25}$. El - pascha- es para los israelitas un pasar por alto en el castigo. Es la hyperbasia, señal de la prohibición de los cultos de otros dioses y exclusión de ellos según las palabras del Exodo "26: "Yo soy el Dios que te saqué de Egipto. No tendrás otros dioses ante mi rostro" ${ }^{27}$. La misma intolerancia de otros dioses implica la prohibición de lugares de culto fuera del Arca y la prohibición de ídolos. Es la TN junto a la afirmación del culto incondicionado del Dios del Exodo: "No usarás el nombre de tu Dios", y el sabatismo, recuerdo de la obra divina creadora ${ }^{28}$.

En el mundo helénico, Jenófanes vio que en los mitos "no hay nada digno, aunque sea noble acordarse siempre de los dioses". En contraste con Homero y Hesíodo, Jenófanes "descubre que los hombres se imaginan los dioses semejantes a los hombres: "Si los bueyes y los leones tuvieran manos y con ella pintaran y trabajaran como los hombres - los caballos iguales a los caballos, y los bueyes iguales a los bueyes - pintarian también las formas de los dioses y les darian cuerpos como los que ellos tienen" ${ }^{29}$. A pesar de todo su mitología y crítica admite esta unidad divina pasando de la negación a la afirmación definitiva de la objetividad inicial de su religiosidad. El énfasis de la crítica de Jenófanes está a la altura del Decálogo, aunque no llega a la intolerancia afirmativa del AT ${ }^{30}$. Es el esbozo griego de la $T N$.

"El daimon, al que se adhiere Sócrates, le dice algo posıtivo. En religión como en política, la crítica socrática se apoya en algo que no piensa poder valorar en forma positiva" ${ }^{31}$. Según el Cratilo, no conocemos nada de los dioses, ni a ellos ni los nombres con que son llamados. Es de creer que entre sí se nombren bien ${ }^{32}$. La tran-

\footnotetext{
24. Cfr. pp. 14-15.

25. Cfr. p. 16.

26. $E x 20,3$.

27. $E x 20,7$.

28. Cfr. pp. 18-24.

29. Frag. 15.

30. Cfr. pp. 24-25.

31. Cfr. p. 27.

32. Cratilo $400 \mathrm{~d}-401 \mathrm{a}$.
} 
sición socrática de la negación fundamental a la afirmación estructural se parece a la $T N$ y tiene en Platón un sentido filosófico con una tendencia a la dialéctica negativa ${ }^{33}$. Platón comienza por lo no-presumible y llega a esta meta final ${ }^{34}$ por la analogía con el sol, fuente de la luz comparable a la idea de Bien ${ }^{35}$. En los escritos posteriores explica su aporía primera ${ }^{36}$, describiendo en el comienzo al Padre de todo como más allá del $\operatorname{ser}^{37}$.

La demostración, según Aristóteles, supone unos primeros principios conocidos, no sabemos si científicamente. El conocimiento fundamental es el nous, que será intención de intención ${ }^{33}$, que es como una arché separable, impasible y pura. Pero desconocemos. si hay otros conocimientos. El lenguaje no basta para el conocimiento lógico de los principios. El conocimiento es más bien un sıgno de la intuición precedente del uno ${ }^{39}$. Las frases empleadas en la Metafísica son bien paradójicas ${ }^{40}$.

Según el judío platónico, Filón de Alejandría, "el principio metafísico-gnoseológico, de que mediante la reducción negativa de un conocimiento positivo debe pasarse a la afirmación de un principio sin comienzo, parece estructuralmente comparable a la tesis fundamental de la $T N$ donde la negación crítica de la idolatría sirve para pasar a la afirmación exclusiva y religiosa de Yahvé" "1. "Filón considera salvífica la actualización empírica de Israel más que como paso de los vicios a la virtud. Pascua significa paso. La explicación del AT debe ser allegoria" ${ }^{42}$.

Si la $T N$ se halla formulada en el AT, ¿por qué no también en el Nuevo? El contenido del kérigma es hipotético. ¿Era la esperanza de la parusia? ¿Era la fe en la resurrección del Crucificado? También sería hipotética la elevación progresista, como la pascua -paso- del $A T^{43}$. El mundo real no se completa en la Historia. Es oscuro como el pesimismo del Kohelet _Eclesiastés- y de Job. De ahí dos momentos para la Iglesia: 1) La ordenación del presente a la esperanza escatológica o realidad completa de la parusía; 2) El paso del recuerdo de Cristo, nuestra Pascua, en la cruz - nega-

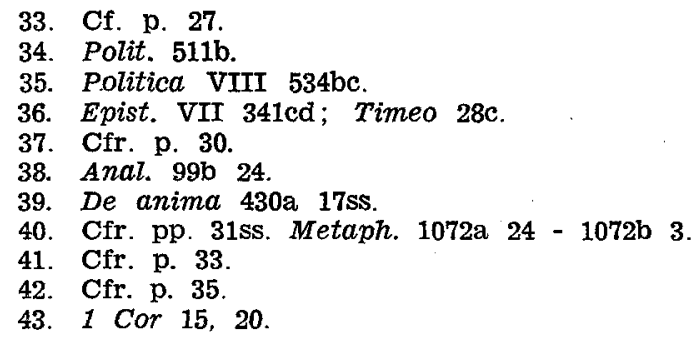


ción- a la afirmación de la parusia ${ }^{44}$. La parusía es el tercer momento afirmativo ${ }^{45}$. Esta es la hipótesis de la $T N$ que tratamos de justificar. Los tres momentos de la $T N$ se hallan en san Pablo ${ }^{46}$ : La palabra de la cruz, Cristo - recuerdo pascual- que predicamos; tontería y escándalo para la ciencia del mundo histórico, que no se realiza - negación- de los judíos y gentiles; fuerza de Dios para los creyentes que esperan. Asimismo ${ }^{47}$, se critican las profecías judias y la gnosis: "Conocemos en parte, profetizamos en parte (recuerdo). Lo perfecto (afirmación) vendrá al desaparecer lo parcial. La plenitud será personal ${ }^{48}$. El tiempo es como si no ${ }^{49}$.

En los sinópticos hay expresiones posteriores al evangelio de Jesús. Así: "Jesús vino a Galilea anunciando el evangelio" 50 es recuerdo de la comunidad postpascual (negación). "Y se acerca el reino de Dios" (afirmación) que puede explicar asimismo la negación: "arrepentíos", y la afirmación: "ya se acerca el reino de Dios". En este sentido Marcos 1,15 podría ser una cita originaria neotestamentaria de la $T N$, en su redacción postpascual de la comunidad, "con su llamada permanente, negación autocrítica y afirmación escatológica", lo mismo que el desconocimiento del último día ${ }^{51}$, con las gracias al Padre por la revelación a los humides, desconocimiento universal (negación) y revelación a quien quiera el Hijo. La TN es ya tan hipotética como en Marcos $1,15^{52}$.

En san Juan ${ }^{53}$ el amor a Dios es presente, no escatológico, como en san Pablo. Pero los tres momentos de la $T N$ se hallan en esta frase: "El Padre es mayor que yo" ${ }^{54}$ como afirmación teológica de Jesús, supuesta una negación crítica. El texto de san Juan 1,18 es una declaración de la absoluta trascendencia de Dios ${ }^{55}$.

En los Hechos 17 hay dos conceptos de TN. El agnóstos theós, según Norden, implica un ataque a la gnosis, aunque el Pablo auténtico de las Cartas admite ese atributo gnóstico en Dios. El autor del discurso supera la incognoscibilidad por el método estoico de la religión popular - vv. 24-29- contra el antropomorfismo he-

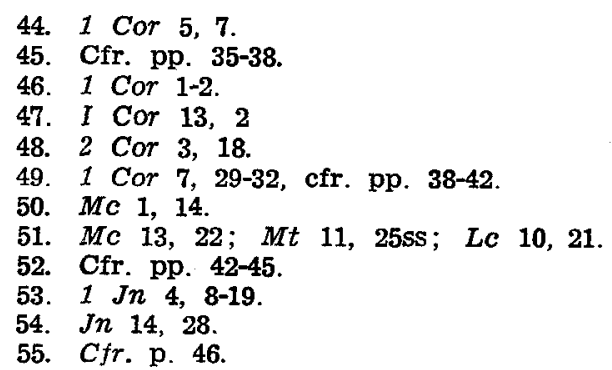


leno. Supone, pues, una fase previa de $T N$ con los tres momentos de la $T N$ cristiana: la creación, la negación de la cognoscibilidad y la afirmación del hecho críticamente demostrado contra los no creyentes en la resurrección ${ }^{56}$.

La gnosis es conocimiento de Dios bueno acósmico y del espíritu de uno mismo, presa del demonio. Es mística dualista de lo acósmico luminoso, y del demiurgo con los arcontes. De espíritus buenos y malos, de los divinos y del hombre, del mundo psíquico y sociopolítico. Su interpretación histórica admite la TN. La gnosis se nos presenta a los modernos revestida de mitos, como dualismo de mito e interpretación, como fábula y afirmación. Los gnósticos iluminados - pneumáticos- se oponen al vulgo de los psíquicos, que viven en la sombra. La gnosis es reencuentro de la salvación perdida con la recuperación de su identidad ídeal, no la identidad real. Es característica la frase: "Deja de buscar a Dios, a la creación y cosas semejantes, y entonces te conocerás a ti mismo". "Yo soy la voz del despertar en la noche". En la antitesis tiempo/eternidad, la gnosis es comienzo perfectivo del hombre, y su fin es la gnosis en Dios. Esto implica una relación mutua antitética de lo absoluto del tiempo, que produce lo absoluto eterno. Como re-experiencia mística, la gnosis es el momento básico del pensar gnóstico ${ }^{57}$.

El platonismo medio y el neoplatonismo están interesados en la crítica antijudía y anticristiana ${ }^{58}$. Así ocurre en Numenio, Celso y Albino. La gradación triádica es tema filosófico en un pensamiento circular reflexivo, que Proclo llama lo esférico del espíritu ${ }^{59}$. Es ascensión trascendental hacia la unidad pensante y reflexiva, cargada de experiencia divina sín distinción de lo nuestro. La TN neoplatónica incluye la connotación del encuentro místico con lo divino.

Numenio hace emanativos los atributos, como Parménides ${ }^{60}$ interpretado metafísicamente por los neoplatónicos. El Uno es arché. Orígenes critica a Celso por determinar a Dios sólo con atributos negativos y vacíos, partiendo del Timeo ${ }^{\text {61: }}$ "Es difícil encontrar al Padre de todo; imposible hablar de él". Según Celso, interpretado por Dörrie, a Dios hay que pensar: a) dando cohesión al resto del mundo, como base suprema; b) separado totalmente de todo lo inferior, y así aparece trascendente; c) en su avance desde aquí hacia allá. Y así es visible como el sol en el reino de las ideas. Es-

\footnotetext{
56. Cfr. pp. 47-48.

57. Cfr. pp. 53-64.

58. Cfr. Vita Plotini, 16.

59. In Tim. 2, 77, 8ss.

60. Parmen. 142a 4-6.

61. Contra Celsum VII 42; Timeo $28 \mathrm{c}$.
} 
tos caminos los describe Albino en diez capítulos, entendiendo la aphairesis como negación preparatoria de la via eminentiae de Plotino ${ }^{62}$.

Los neoplatónicos no identifican experiencia mística y reflexión trascendental. Lo Uno místico está más allá de todo ser y concepto ${ }^{63}$. No es el pensar del pensar; está más allá del pensar. "Deja todo si quieres nombrarle", escribió Plotino ${ }^{64}$. Para una perfecta afirmación de lo divino hay que negar toda determinación pensable. Se le Ilama bueno por necesidad. Así queda sólo la $T N$. No se sube de lo inferior a lo superior. "El Uno, el Espíritu y el Alma son en si tres esencias originarias". En último término, la $T N$ no tiene sentido teorético, sino mistagógico. El alma filosófica desea la unión mística con lo divino ${ }^{65}$. La no-identidad del alma con Dios, base de la $T N$, es también su punto de arranque, para llegar a la unión mística, no por vía científica sino con sentido mistagógico ${ }^{66}$.

Los padres de los siglos primeros admitieron gradual e Implícitamente la $T N$. A finales del siglo V, ya explícitamente. En el siglo II. Atenágoras defendió a los cristianos acusados de ateísmo e inmoralidad atribuidas por Frontón de Circa, Luciano y Celso. La TN se trasluce en Arístides y en la Carta a Diogneto, al llamar a Dios incomprensible y apuntar al argumento positivo de la praxis divina. Arístides afirma conocer a Dios Creador del mundo, mas no su naturaleza, y pasa a examinar las creencias verdaderas o falsas del género humano. Lo mismo proceden Justino, Atenágoras, Teófilo y Clemente Alejandrino, recurriendo a la Escritura. Su actitud conciliadora tiene expresiones alusivas a la gnosis. Así dice Clemente: "El Señor Dios era inefable, pues no se habia hecho hombre todavía. En la presencia divina está el Logos, por el cual Dios se hace visible y manifiesto" " "Pero una cristología teológica del Logos no es soteriológica, sino cristología metafísica" ${ }^{68}$.

La $T N$ tenía el riesgo gnóstico-heterodoxo de considerarse como una vivencia previlegiada y no el hecho salvífico de la fe por el Evangelio y la Iglesia. De ahí el ataque de Ireneo ${ }^{69}$ al establecer la diferencia entre la gnosis y la trascendencia de la fe, y censurar la petulancia de los gnósticos y sus mitos, al atribuirse a sí mismos

\footnotetext{
62. Cfr. pp. 74-76.

63. En. VI 8, 19, 3ss.

64. En. VI 8, 21, 23-33.

65. Cfr. En. VI 7, 31.

66. Cfr. pp. 79-81.

67. $P G 8,320 \mathrm{~A}$

68. Cfr. pp. 85-90.

69. Adv. haer. II.
} 
un conocimiento que niegan al Creador. Los cristianos, en cambio, ven en Cristo al gnóstico verdadero y con él -en posición inferior- la jerarquía angélica y eclesial. Según Ireneo la $T N$ está implícitamente en la regla de fe. Explícitamente no aparece aquí por vía racional, sino sólo en la revelación positiva de la escatología ${ }^{70}$. Ortodoxos y herejes se acusaban de idólatras.

Gregorio de Nisa y Basilio atacan la $T N$ de Eunomio y de Arrio por llamar incomprensible sólo al Padre, negando la divinidad del Hijo. En cambio, los herejes atacan la $T N$ ortodoxa porque niegan la divinidad del Padre al equipararle con el Hijo. Los padres toman la $T N$ del neoplatonismo, como algo mistagógico, criticando la superstición platónica y pagana. Así Orígenes ${ }^{71}$ y Gregorio de Nisa, en el ideal humano de ser con Cristo imagen de Dios por el alma ${ }^{72}$. El Nacianceno, que une la $T N$ a la praxis, critica a Platón radıcalizando su sentido ${ }^{73}$, y desfigurando el sentido de Platón. Su pensamiento puede verse en el carmen $29^{74}$.

El Niseno da un enfoque original a la $T N$ como empresa infinita del hombre en la búsqueda de Dios, donde cada avance es superado por otro en dirección a Cristo, semejanza perfecta del $\mathrm{Pa-}$ dre incomprensible e infinito. En el Cantar de los cantares, el amante es la Iglesia que va en pos de Cristo, que es la revelación. En la teofanía de Moísés explica cómo la trascendencia, buscada como absoluto, se queda en la relativa, cuyo complemento es la afirmación escatológica. El Niseno parece ser el primero en ver la $T N$ en el Decálogo, cuando Moisés entra en la nube para tratar con Dios, y conoce el respeto absoluto que se le debe sin penetrar en su esencia. Del respeto proceden las normas de la relación con Dios y el amor debido al prójimo. En su exposición segunda, lo primero es no aplicar a Dios nada creado, superando así la $T N$ neoplatónica. La $T N$ cristiana es superior no sólo al pensamiento sino a toda la existencia humana.

Apophasis y Theologia aparecen unidas en el Ps. Areopagita ${ }^{75}$.

La Tn alude tal vez a Act 17, 22-24. Theologia apophatica es reflexión centrada en la Trinidad partiendo de la Theologia symbolica ${ }^{76}$, aplicando a Dios amorfo figuras sensibles, to cual es absur-

70. Cfr. pp. 91-98.

71. Contra Celsum VII 44.

72. Según. Gn 1, 26 y Col 1, 16.

73. Cfr. Timeo 28c y Orat. 28, 4 PG 36, 29C - 32A.

74. $\quad P G$ 37, 507ss, cfr. pp. 105-108.

75. Sobre el anonimato eclesial cfr. J. A. Sint y K. Aland, en los articulos que vamos a citar en la nota 128.

76. $C H$ 336A; $D N 597$. 
do. Hay símbolos conformes a Dios -logos, nous, essentia-, pero hay otros semejantes, como los sensibles ${ }^{77}$. Pero no hay nous que le sea semejante, ni término apto. Son preferibles los negativos -infinito, incomprensible, etc.- fundados en la Escritura: en la via negationis. Las figuras desemejantes llevan a la oscuridad. El Areopagita depende de la Biblia, pero recibe influencias de la alegoría neoplatónica y filoniana ${ }^{78}$.

La Theologia mystica lleva el título: “Cuáles son las teologias Katapháticas y cuáles las apopháticas?". En el texto se lee: "¿Por qué comenzamos por la negación de lo último y por la afirmación de los primeros? Para establecer la afirmación básica poniendo lo supremo de todo, lo más cercano de él. Mas cuando negamos sobre lo supremo toda negación, debemos negar al principio lo más alejado de él ${ }^{79}$. La negación es necesaria al reflexionar en el principio divino. La afirmación tiende a explicar los efectos de dicho principio. En la negación sigue a Albino y a Celso, inspirándose en Proclo.

Con la $T N$ llega de la negación a la afirmación subiendo de lo desemejante a lo semejante mediante negaciones sucesivas en un proceso hierarcológico. Otro título ${ }^{80}$ parecía referirse a principios teóricos, equiparando lo kataphático a lo deductivo, y lo apophático a la inducción. Mas las hypotyposeis -fundamentos- dan la preferencia a lo negativo. La $T N$ del Areopagita no es soteriológica, sino un método de reducción al principio superunificado de la Trinidad divina, misterio superior a todo nombre, accesible sólo por negación. La Teología divina, misterio superior a todo nombre, accesible sólo por negación. La Teología positiva es el momento preliminar, es Dios que se presenta y hace reflexionar ${ }^{81}$.

En Theologia mystica la kataphasis responde a manifestación divina de la creación y de la revelación, expresable sólo por simbolismos inadecuados, que han de corregirse. El momento segundo es la $T N$, eliminadora de las desemejanzas. Santo Tomás evita la falsa interpretación o contradicción de ambos momentos unificando las dos fases. El tercer momento es superación y supresión de los dos primeros con una afirmación superior. Algunos autores ven en la $T N$ un rasgo discursivo esencialmente diverso de la contemplación. Otros lo creen excesivo: la $T N$ sería la preparación de la posesión

\footnotetext{
77. $\mathrm{CH} 140 \mathrm{C} ; 1105 \mathrm{D}$

78. Cfr. pp. 121-127.

79. $T M \quad 1033 \mathrm{C}$.

80. $T M$ 1032C.

81. Cfr. pp. 130-135.
} 
mistica. Tal es la anticipación de la apophasis. La TN tiene en Dionisio un sentido mistagógico. La theologia apophatica debe ser la ley fundamental en el pensamiento moderno, como principio básico de esta teología ${ }^{82}$.

"La jerarquia en general —según nuestra tradición- es el sistema global de los momentos salvíficos reales". Es el Logos tradicional, un concepto ordenador, una categoría de gradación jerárquica, que comienza en la Trinidad, fuente de la vida. Dionisio concibe la acción jerarquizada salvífica de Dios, sin duda, según el modelo neoplatónico de la emanación a escala trinitaria. Es jerarquía cíclica, como en Proclo, corregida de su emanatismo por Máximo el Confesor. Los teólogos con frecuencia han ignorado este carácter categorial, entendiéndolo como una jerarquía eclesiástica de dignatarios. El Niseno sólo conoció la trascendencia insuperable de lo absoluto y lo relativo. En la escala areopagítica, el grado inferior tiene algo del superior entre hombres y ángeles, con simas insalvables, pero abiertas ${ }^{83}$. Sólo es inaccesible la sobresustancial y oculta divinidad, a no ser que la Thearchia introduzca en el misterio ${ }^{84}$. Por el contrario, en sus manifestaciones Dios puede comunicarse analógicamente. Este es el sistema jerarcológico ${ }^{85}$.

La jerarcología de la $T N$ tiende a la unificación de los componentes emanativo y especulativo neoplatónico realizados en cada grado angélico o humano, segủn su capacidad ${ }^{86}$. En el pensamiento jerarcológico de la $T N$ lo salvífico llega por negaciones ascendentes a una afirmación superadora de lo kataphático y de lo apophático o negativo ${ }^{87}$.

La salvación y la Trinidad son el tema propio de la $T N$ de Dionisio. De ahi el peligro de monofisitismo al hablar de la esencia divina de Jesús, al venir de la eternidad al tiempo por amor al hombre ${ }^{88}$. El misterio de Jesús permanece oculto, en forma peligrosa, por no decir más ${ }^{89}$. En su moral se distinguen los purificados, los que purifican y los iluminados ${ }^{\circ 0}$. En la $T N$ no aprende, se padece. Sorprende la aplicación de la $T N$ a la jerarquía sacerdotal eclesiástica, que no sufre imperfección. Con esta bravata justifica su elevación de la $T N^{91}$.

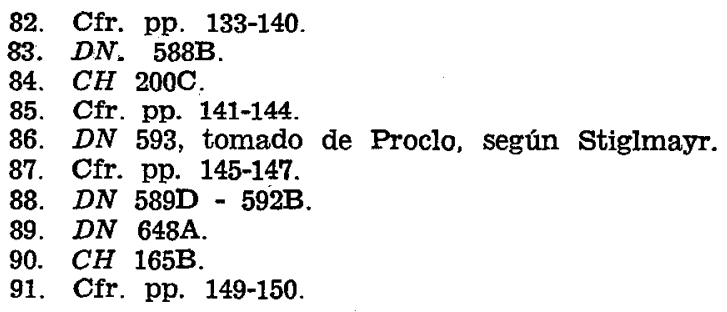


En la tradición posterior destaca Máximo el Confesor que corrige el peligro emanatista de Dionisio al poner en Dios ontológicamente modelos preformados de los seres creados ${ }^{92}$, e introduciendo en la teología la participación platónica. EI IV Concilio de Letrán (a. 1215) adopta la interpretación de Máximo el Confesor declarando que los fieles reciben por la gracia la unión y perfección divina y enseña que en los seres creados no hay semejanza divina no contrarrestada por una desemejanza mayor. La TN del IV Concilio de Letrán ha sido recibida por la tradición católica ${ }^{93}$.

En el aspecto semántico - según Wittgenstein- en lo inefable hay que callar. No se debe aceptar nada inefable, como tampoco lo mítico. La TN no debiera ser TN. No cabe hablar de ella, según Wittgenstein. Bochenski no halla contradición sino insuficiencia en lo inefable o $T N$. Puede haber $T N$. No es absurdo que $d$ sea inefable en un lenguaje y que sea expresable en otro. La inefabilidad será objeto de los metalenguajes. Mas, según Witgenstein, un metalenguaje ha de ser determinable en el lenguaje común. Ahora bien, la $T N$ dice que lo inefable es indecible aún en el lenguaje común. Lo cual es un contrasentido. Por tanto no cabe en el objeto de la religión, y resulta inadecuada la misma observación sobre la insuficiencia de la $T N$. Witgenstein es más claro que Bochenski: "No se puede adorar, si se acepta que carece de toda propiedad positiva"

Entonces ¿puede tener la $T N$ un sentido funcional religioso? Un mundo secularizado sólo lo admitirá en forma estructural entre interlocutores competentes. No basta la necesidad a priori de la lógica trascendental de Kant, como conocimiento que a priori determine su origen y su valor objetivo, como pretendió Kant para dar lugar a la fe. Es problema que afecta a la TN. Husserl deja a un lado la subjetividad psicológica y exige una subjetividad trascendente extensible a todo sujeto cognoscente. "Este sustrato es para él la subjetividad anterior al ser del mundo, al que constituye en su sentido óntico" 95. De donde resulta que la afirmación y la negación sólo se relacionan en el límite de la posibilidad del conocer y del obrar, suponiendo primero un sentido apriorístico; segundo, a mutua relación; y tercero, el carácter conjetural a priori de la síntesis. Kant en su pura percepción del Yo pienso, supone que la propia identidad es la primera unidad trascendental afirmativa. El sentido de la negación radical se experimenta ante el vacío y la nada. Mas

\footnotetext{
92. $P G$ 91, 1081AB y 1329 .

93. Cfr. pp. 149-157.

94. Cfr. pp. 159-164.

95. Cfr. p. 168.
} 
en la negación va la intención y la esperanza impulsora de la acción. En vez de afirmar, se teme: es el polo opuesto.

"La condición a priori que posibilita el quehacer moral es la reacción anticipación-retracción de la afirmación incondicional para lograr la identidad del yo y la salvación del mundo" ${ }^{6}$. Así se llega de un modo nuevo a la afirmación combinada con la negación. Desde Kant se llama antinomia a la contradicción de carácter trascendental, que no se prueba pero se entiende en el espacio y en el tiempo por la espontaneidad de estos conceptos regulados por las categorias del puro intelecto.

De las cuatro antinomias, la tercera es ésta. Tesis: La causalidad de las leyes físicas no es el origen único del mundo. Antítesis: No hay libertad. Todo ocurre según las leyes de la naturaleza. Es posible que el intelecto traspase las fronteras de la experiencia al incurrir en esta antinomia de naturaleza y libertad. A Kant no le preocupa el tema. ¿No estará aquí el origen de TN? Kant supone a priori que el Sumo Bien es producto de la libertad en la antinomia mental. La $T N$ comienza por tener sentido y termina en un contrasentido ${ }^{97}$.

La negación radical del intelecto puro es una llamada a la afirmación postulada por el intelecto práctico en orden al Bien supremo, que postula inmortalidad, y ésta postula la existencia de Dios. "Yo tenía que suprimir el saber para dejar sitio a la fe", dirá Kant. La limitación del intelecto respecto a lo suprasensible se llama critica de la fuerza crítica. La contigüidad lógica trascendental del sentido y contrasentido de la $T N$ en lógica formal es una "simultaneidad". Luego la $T N$ en su significado verbal es tanto el concepto básico de la Teología como el conjunto de la negación posible de toda teología. "Con esto la aportación lógica-trascendental termina con una aporía. La $T N$ debe formularse como una teoría pragmática universal" 98 .

Hegel transformó la antinomia kantiana en dialéctica especulativa, como método absoluto del saber, inmune al principio de contradicción, y como explicación evolutiva autogeneradora del hombre. Marx no acepta la Dialéctica especulativa, pero sí el antagonismo dialéctico de las fuerzas sociales. Para Adorno la Dialéctica negativa ha de connotar la afirmación. Este fenómeno constituye la trascendencia relativa, lograda en la combinación del lenguaje objetivo matemático y el pensamiento comunícativo de la cortesía, cuan 
do se habla sin decir nada. El conjunto de objetividad y comunicación es verificable en el monólogo y en el diálogo que exige monólogo. En esta dialéctica cabe la trascendencia relativa, donde una negación monologal puede ser superada por el diálogo universal del lenguaje común, determinando nuevas situaciones en que el lenguaje común absorbe y supera las negaciones monologales precedentes ${ }^{99}$.

La dialéctica social, introducida con el lenguaje común, hace que diversas personas se comuniquen sobre objetos idénticos. Su relación con el objeto no puede ser puramente teórica, dada la interferencia de intereses individuales en el diálogo. Teoria y praxis constituyen dos momentos de la Dialéctica con la signatura de la trascendencia relativa. El cambio teórico-social introduce exclusiones y fomenta la libertad. Kant atisbó la dialéctica social. Hegel la enriqueció con el espíritu del pueblo, acumulando reaciones teóricoprácticas. El impulso histórico inicial dado por la libertad no coincide con la necesidad física. Introduce la trascendencia relativa, pero deja atrás múltiples cuestiones insolubles. No se puede reducir la Dialéctica a la Historia.

La Dialéctica, extraña a la Historia, ha fracasado. No cabe una dialéctica entre el dolor y la esperanza. Ante este fracaso ha habido tres reacciones: 1) supresión de la Historia como teoría y praxis. Negar la teoria histórica no es serio: equivale a identificar la ciencia con el poder, y el séquito de crueldades, guerras y muertes de la tecnocracia absolutizada; 2) frente a esto el marxismo recurre a la Historia como praxis orientada a la revolución del proletariado, que desemboca en totalitarismo. Esta segunda teoria de la Historia se completa o plenifica a sí misma en el totalitarismo marxista; 3) hay teóricos, como Teilhard de Chardin, que piensan que la naturaleza se plenifica ella misma y se hace historia. También Marx habla de una resurrección de la naturaleza. La escuela de Frankfurt y J. Habermas promueven esa dialéctica natural entre naturaleza e Historia. Otros, como Bloch, son más cautos. Es un postulado desacreditado por el sufrimiento propio de la Dialéctica negativa, expuesta por Adorno ${ }^{101}$.

La $T N$ podría formular la Dialéctica negativa, situándose al fin de la Historia. Por ahora es un misterio oculto en la Pasión de Cristo y su resurrección. Es misterio realizado, pero oculto, base de esperanza, que no separa la memoria mortis de la memoria resurrec-

99. Cir. pp. 189-192.

100. Cfr. pp. 196-197.

101. Cfr. pp. 198-204. 
tionis. Esto no es gnosis ni mito. Son hechos. El mysterium factum paschale, base de esperanza, Dialéctica misteriosa basada en la Trinidad ${ }^{102}$, es un postulado de la teoría óntica reducida a postulado práctico-crítico, reservado por Dios a la escatología crìstológica, dependiente de la teología de la historia. La $T N$ consiste en que la historia fracasa siempre, pero Dios la concluirá en su providencia escatológica ${ }^{103}$.

Son tres momentos los de la $T N$. El momento básico es el recuerdo de la muerte y resurrección. "El primer momento del concepto de la $T N$ ha de ser una negación radical". En el momento segundo se pasa a la afirmación. "Una cristologia puramente afirmativa seria inconciliable; quedaria en pura mitología". Sería cristología de arriba; pero debe completarse con la de abajo". En la pasión y muerte de Cristo adquirirá consistencia y visibilidad el empeño siempre fracasado del hombre en la historia". La escatologia cristológica fundida en la Historia debe ser disciplina básica de toda teología cristiana. El análisis de la TN señala el camino teóricopráctico de toda praxis, esperanza y amor. La $T N$ es el modo de pensar de la fe cristiana. La $T N$ es el Logos que pasa al ethos. No es un modo de pensar psíquico. De la $T N$ jerarcológica se podrá decir que no es posible sin una negación universal que connota un objeto inefable. La TN lógico-trascendental es la última condición subjetiva de la filosofía religiosa. Para nosotros la $T N$, como pensamiento teológico, contiene la Dialéctica negativa como meta-historia, orientada a la libertad ${ }^{104}$.

La $T N$ es punto de arranque para la problemática moderna de la fe: 1) En la teodicea centrada en el dolor. 2) En la ausencia de Dios en la sociedad, que arranca del dolor. 3) En el humanismo cristiano y moderno, superación del dolor. El cristiano aborda el fenómeno universal del dolor con la esperanza escatológica de la $T N$, como negación orientada a la afirmación de la esperanza, basada desde el cristianismo primitivo en el amor de Dios y del prójimo, no como sentimiento de misericordia, sino como superación práctica del dolor y de la injusticia ${ }^{105}$.

El ateísmo moderno silencia, no ataca, el nombre de Dios, como científicamente inútil y moralmente imposible. El cristiano resiste a la tentación con la plegaria, reduciendo el problema a la escatología de la $T N$. Es el momento primero con los recuerdos de la ausencia de Dios en Getsemaní y en la Cruz. Es la noche oscura

\footnotetext{
102. Gal 16, 14; 2 Cor 5, 18ss.

103. Cfr. p. 214ss

104. Cfr. pp. 219-223.

105. Cfr. pp. 226-227.
} 
mística. El momento segundo de la esperanza es irrenunciable. EI amor del humanismo cristiano es incompatible con el ateísmo. En el amor se encierra la afirmación de Dios y de su reino. Es también la respuesta al superhombre de Nietzsche y el proletariado marxista $\sin$ clase ${ }^{106}$.

El autor señala en su obra los tres momentos: negación, llamada a la afirmación, y afirmación, conciliando la afirmación con el pensamiento moderno sobre el dolor, iluminando con el misterio realizado de la memoria de la pasión y muerte dirigido a la escatologia, dando asi sentido a la historia. Es la forma del pensamiento cristiano de estructura bipolar de negación y afirmación, que supera el fracaso experimentado por todo hombre en la Historia mediante el amor de Dios y del prójimo. La $T N$ hace ver a los hombres que, a pesar de sus fracasos en el dolor, pueden abrigar cierta esperanza ${ }^{107}$.

\section{Juicio histórico doctrinal}

El método expositivo, seguido por el autor, es lo primero que debemos analizar en el estudio amplio y denso de la hipótesis conciliadora de la $T N$ que acabamos de resumir. Prescindiendo de las lagunas y omisiones inevitables en una sintesis conceptual tan compleja, es preciso enjuiciar la marginación sistemática del influjo estoico en la $T N$. Es una eliminación que parece consciente y premeditada, tanto por la afinidad del Logos estoico y el Dabar bíblico, con la Palabra evangélica y el Verbum de san Juan, como por el influjo del estoicismo en la $T N$ areopagítica, a la que Hochstaffl atribuye una importancia excepcional. En su bibliografía figuran los estudios de Hornus ${ }^{103}$.

Mas la diferencia principal entre el método de Hochstaffl y

\footnotetext{
106. Cfr. pp. 231-232.

107. Cfr. p. 237.

108. Cfr. J. M. Hornus, "Pseudo-Denys l'Aréopagite et la mystique chrétienne", Revue d'Histoire et de Philosophie religieuse 27 (1947) pp. 37-63; "Les recherches récentes sur le Pseudo-Denys l'Aréopagite", Revue d'Histoire et de Philosophie religieuse 35 (1955) pp. 404-448; "Les recherches dionysiennes de 1955 á 1960", Revue d'Histoire et de Philosophie religieuse, 41 (1961) pp. 22-81. De especial importancia son los dos últimos articulos por los datos recopilados y enjuiciados - siempre con un juicio matizado y ponderado- de más de 30 autores y más de 51 trabajos, con alusiones a otros trabajos, cuyo conjunto llega aproximadamente al centenar. Es la bibliografía areopagírica prácticamente exhaustiva de los años 1930-1960. Hochstaffl la tiene en cuenta, y en sus apreciaciones desfavorables al Areopagita es fácil que dependa o concuerde con algunos de las criticas examinadas por Hornus, aunque sin la matización sumamente correcta del Prof. Hornus, que pertenece a la Iglesia Protestante del Libano.
} 
Hornus no está en los juicios más o menos divergentes y en sus matices. El Prof. Hornus expone con gran objetividad los argumentos básicos de los trabajos reseñados, aunque a veces no admita las conclusiones, dejando asi la posibilidad de avanzar en una investigación posterior. Con este criterio expone y recoge, suscribiendo sin vacilación alguna, el influjo ejercido por el estoicismo en la doctrina areopagítica, y sin retroceder ante las consecuencias embarazosas que este hecho histórico pueda acarrear en contra de las tesis más corrientes acerca de la autenticidad del Corpus dionysiacum.

Hornus, con la opinión corriente, se inclina a creer que el $C D$ se compuso a principios del siglo $\mathrm{VI}$, cuando el estoicismo había desaparecido sin dejar apenas rastro en la filosofía, ya que aun los mismos escritores neoplatónicos habian abandonado el sistema estoico. Así Pohlenz - a quien no cita Hochstaffl- hace ver que Plotino podía tomar muy poco de los estoicos ${ }^{109}$. Porfirio pudo inspırarse en la doctrina sobre la apatheia y Proclo no tomó prácticamente nada de ellos ${ }^{110}$. Para apreciar las consecuencias de ausencia del concepto dinámico, eficiente y creador de la Palabra o Verbo en la teologia, basta reparar en que la inefabilidad de la $T N$ humana es una deficiencia de nuestro lenguaje, en que nos reconocemos incapaces de decir lo que Dios es-dice-hace con su Palabra omnipotente. Es el reconocimiento de que Dios en su ser y en su Palabra - Verbum - tiene una eminencia activa y dinámica esencial sobre nosotros. Es la hyperoché causal y eficiente del sistema areopagitico que por su afinidad con el Logos estoico hemos estudiado en otra ocasión ${ }^{111}$.

El concepto estoico cristianizado de la hyperoché causativa, ausente en Plotino, reaparece en Proclo, pero no como eminencia puramente cósmica, no-eficiente, como ocurre en $C D 1072 \mathrm{~b}$, donde el Areopagita habla de la apophasis hyperochiké, o inefabilidad supereminencial causativa de Dios. La ausencia de este elemento estoico cristianizado en la $T N$ apophática de Hochstaffl resulta sin más incompatïble con la Escritura, con el Areopagita y con la tradición escolástica posterior. Es una omisión irremediable de la hipótesis conciliadora de la $T N$. Sin el elemento activo de la Palabra divina resulta imposible entender el carácter unitivo de la Teolocia kataphática o afirmativa de la naturaleza de Dios y de su Trinidad. y de la persona divino-humana de Jesús, y el carácter también unitivo que la misma inefabilidad de la apophasis en su forma ascen-

109. Die Stoa, vol. I p. 391.

110. Cfr. Die Stoa pp. 197-399.

111. Cfr. El estoicismo, vol. I pp. 230-237. 
dente tiene para nosotros la $T N^{112}$. Este carácter eficiente y unitivo ha de aplicarse a la misma comunicación cognoscitiva producida por la Palabra de Dios, y la comunicación sacramental que verifica en la invocación trinitaria bautismal transformadora del hombre como miembro de Cristo, y sobre todo en las palabras de recuerdo mio de la consagración eucaristica, donde el Areopagita observa que el recuerdo tiene eficiencia sagrada - hierarchica- verdadera, no puramente mistérica o cultual como en los ritos paganos ${ }^{113}$.

El sistema lingüístico-cognoscitivo subyacente en el $C D$ resulta anacrónico -y prácticamente imposible, salvo la posibilidad muy discutible de fraudes ideológicos sistematizados- en el siglo V. Desde que a fines del siglo III, Porfirio introdujo en su Isagogé la duda sobre el carácter real o irreal de las categorías airstotélicas ${ }^{114}$, no sólo resultaba utópico el realismo activista del Verbo estoicocristiano, sino aún el realismo formalista griego de Platón y de Aristóteles. El principio de contradicción, que en Aristóteles se reducía a la imposibilidad psicológica de pensar al mismo tiempo en formas contrarias, pasó con Porfirio a principio lógico metafísico. En el $C D$, en cambio, resulta absurdo que el Verbo de Dios -incluso el pensamiento esencialmente dínámico de Dios - sea verdadero y falso, activo y no activo. Estos datos son necesarios para plantear la posibilidad o imposibilidad de que alguien hacia el 500 pudiera introducir de contrabando el fraude literario de $C D$, atribuyéndolo a Dionisio Areopagita, discipulo de Pablo. ¿Hubo tal fraude?

Para proceder con imparcialidad comenzaremos por el balance de opiniones de Hornus, el más objetivo que poseemos, aun cuando siga una corriente discutible. Hornus dedica, en efecto, una importancia primordial a los escolios de Juan de Escitópolis, conservados por Máximo el Confesor, recapitulando las investigaciones de Urs von Balthasar ${ }^{115}$. En la página 39 , después de aludir a Corsini, que desfigura su pensamiento, dice "que la fermeture de l'école d'Athènes, raison prétendue de la remise à jour du $C D$ est seulement de 529 , alors que Sevère connaissait déjà cette oeuvre plus de dix ans auparavant", y añade: "Il faut cependant reconnaître que le commentaire de Jean, bien mis en valeur par Elorduy ${ }^{116}$ cadre remarquablement avec l'hypothèse de ce dernier", es decir el $C D$ es obra de Ammonio Sakkas.

112. $C D$ 1032-1033.

113. $E H \quad 441 \mathrm{C}$.

114. Cfr. $E l$ estoicismo, vol. I, pp. 199ss.

115. Cfr. Revue d'Histoire et de Philosophie religieuse (1955) pp. 416-447, у (1961) pp. 36-40.

116. Ammonio Sakkas I, p. 517. 
En efecto, el punto crucial de la controversia, según Hornus y otros muchos críticos, entre los cuales pienso que figura el mismo Hochstaffl, es si el escolio de Juan de Escitópolis recogido por Máximo el Confesor es la pieza clave del fraude, cuyo cómplice principal sería el mismo Juan, o constituye el documento histórico más antiguo, completo y fidedigno de lo que hacia el 520 se sabía o discutía sobre el tema. Lo que en dicho escolio defiende Juan se reduce a tres afirmaciones: 1) EI $C D$ es obra de Dionisio Areopagita, discípulo de Pablo; 2) Hay quienes lo creen de un pseudónimo posterior; 3) Los paganos, como Proclo, han copiado doctrinas y frases del $C D$ atribuyéndolas a sí mismos. El punto segundo, indicado por nosotros anteriormente ${ }^{117}$, no creo haya sido suficientemente apreciado por los críticos, que no se fijan en la discusión aludida por Juan.

La frase debe ser copiada, por su importancia: "Al decir algunos que el escrito no es del santo, sino de alguno de los posteriores -metagenesteron - les es necesario señalar a alguno de los rechazados y extravagantes, que finge tales cosas de sí mismo, su convivencia con lo apóstoles, y correspondencia escrita con ellos, sin haberlos tratado ni escrito" 118.

Como apunta Hornus, a nuestro modo de ver, ese autor que finge amistades, trato y correspondencia que no ha tenido, y por otra parte es un sujeto no encuadrado entre los personajes oficiales de la Iglesia, se halla descrito con gran propiedad en la Carta a Policarpo ${ }^{119}$, como criticado al mismo tiempo por cristianos y paganos, por no atacar al bando opuesto y encaja en la persona de Ammonio, maestro de filosofía nueva y original para cristianos y gentiles, con cuya amistad se honraban todos, pero quedando al mismo tiempo comprometido, como ocurría con el Obispo Heracles y con Orígenes en escenas recogidas por Eusebio ${ }^{120}$ y Focio ${ }^{121}$, en las que Ammonio aparece al mismo tiempo como vitando y sumamente apreciado por la Iglesia. También en la Vita Plotini, donde se le margina y se le ensalza al mismo tiempo.

El escolio de Juan de Escitópolis es un refrendo justificativo de esta situación anómala y contradictoria del autor del $C D$, conocido según parece con el doble nombre de Ammonio y de Dionisio. Esta misma anomalia recurre en otro escolio del mismo Juan de Escitópolis, donde utilizando apuntes de Dionisio Alejandrino, su-

117. Ibid.

118. $P G$ 4, 21B

119. Cfr. 1077B - 1081C.

120. Hist. Eccl. VI 19, 13.

121. Interrogationes decem 9 PG 104, 1229. 
cesor de Heracles, pregunta al escoliasta con curiosidad: ¿Por qué el divino Dionisio - Areopagita- impugnó a Orígenes por defender éste la unidad de especie de los seres angélicos? ${ }^{122}$.

La hipótesis del sobrenombre usado en el siglo III para designar a Ammonio-Dionisio Areopagita, lo mismo que el doble o triple nombre de Porfirio-Basilio-Malco, o el de Máximo en Megales por Numenio, está garantizada tanto por el escolio aludido anteriormente, como por el trozo del $C D^{123}$. De este paralelismo me escribía el P. Ceslao Pera, en una carta privada del 1 de noviembre de 1959: "La famosa lettera a Demofilo col suo raffronto con la lettera di Dionisio Alessandrino, dall'esame dei manoscritti potrebe segnare un punto fermo di ricerca per decidere se l'uno dipende dell altro o ambedue da un terzo". A la misma conclusión llega el pasaje de Leoncio Bizantino, donde se cita a Dionisio Areopagita entre Hipólito de Roma y Metodio ${ }^{124}$.

Sumando estos datos con otros publicados en otro lugar ${ }^{125}$, creemos anticipar de algún modo la publicación del segundo vol. de nuestra obra Ammonio Sakkas ${ }^{126}$ para dirimir la cuestión de la identidad del Ps. Areopagita con Ammonio, suscribiendo el resto de las conclusiones sobre la no apostasía y otros escritos de este personaje. El estudio replanteado a base de los escolios de Juan de Escitópolis aclararía el sentido del Coloquio Constantinopolitano de Hipacio con los monofisitas, donde ambas partes se muestran enteradas de la discusión existente sobre la identidad del autor del $C D$ con el Areopagita o con otro pseudónimo posterior ${ }^{122}$.

Una vez aceptada la probabilidad de un Ps. Dionisio del siglo III, pierde su valor el dilema tradicional con que últimamente, sobre todo desde Koch y Stiglmayr, se plantea la áutenticidad del $C D$, atribuyéndolo necesariamente al Dionisio Areopagita, discípulo de Pablo o a un pseudónimo del 500 conocido de Juan de Escitópolis. Las consecuencias doctrinales de atribuir el $C D$ a un pseudónimo del siglo III o del IV tienen una trascendencia que hoy se puede medir teniendo en cuenta los estudios sobre el pseudonimato de los siglos primeros ${ }^{123}$. El pseudonimato cristiano descrito por Aland y

122. $P G 4,60$

123. Epist. VII a Demòfilo, cfr. Ammonio Sakkas I, pp. 490 ss.

124. Cfr. Ammonio Sakkas I, p. 522.

125. "Ammonio en las Catenas", Estudios Eclesiásticos 44 (1969) pp. 383-

432. "El neoplatonismo", Historia de la Espiritualidad, vol. IV pp. 311-373.

126. Cfr. H. Rahner en Zeitsch. für kath. Theol. (1962) pp. 123ss.

127. Cfr. Ammonio Sakkas I, pp. 520-521.

128. Cfr. $\mathbf{K}$. Aland, "The problem of anonymity and pseudonymity in Christian literature of the first two centuries", Journal of Theological Studies 12 (1961) pp. 39-49; J. A. Sint, Peudonymität im Altertum. Ihre Formen und Gründe (Innsbruck 1960). 
Sint, tiene el rasgo peculiar de un género literario imbuído en el estilo e inspiración de los escritos sagrados y de la misma predicación evangélica. Frente a este pseudonimato cristiano y carismáti$\mathrm{co}$, el pseudonimato del siglo $\mathrm{V}$, atribuido por Hochstaffl y otros críticos que mantienen el carácter falsario del $C D$ está imbuido en la mitología y mistagogía pagana artificialmente disimulada por el PS. Areopagita, imitador del gran mistagogo Proclo.

De ahí que puedan sorprender las críticas desfavorables relativas a la $T N$ del Ps. Areopagita acumuladas por Hochhstaffl lo mismo que al $C D$ en general por otros críticos, al considerar al $C D$ inspirado en Proclo ${ }^{129}$.

Obsérvese que el pseudonimato tiene puntos de partida inicial y final diversos, según sea un recurso adoptado hacia el 200 o hacia el 500. En el 200 los cristianos son todavía enviados de Cristo, que predican como corderos en medio de lobos, entre hostilidades religiosas y persecuciones sociales y políticas, con la confianza de no preocuparse de lo que han de decir ante los jueces y ante los reyes, porque el Espíritu les dará lo que han de decir en aquella hora. Es palabra eclesial, oficial o privada, canónica o apócrifa, que brota del Verbo de Dios. De ahí el anonimato, pues carecería de sentido anunciar en nombre propio doctrinas recibidas de Cristo por los apóstoles. Esta mentalidad entra en crisis hacia el 200, con el crecimiento de la Iglesia. Clemente de Alejandría proclama la conveniencia de escribir en la forma habitual de la cultura corriente. Longino, casi con palabras copiadas de Clemente, critica a los cristianos por no escribir en la forma habitual. En esta coyuntura tienen sentido las excusas pedidas para no ser considerado como un temerario al escribir, pues sólo escribe lo recibido ${ }^{130}$.

Según esto, no importa el nombre del autor del $C D$ que se limita a divulgar únicamente la doctrina recibida de los apóstoles. Esta es la posición fundamental de la doble opinión debatida por Juan de Escitópolis. Sólo en ese sentido se superará la dificultad sobre la autenticidad apuntada por Hipacio el año 531/532, y podrá ser recibida la doctrina areopagítica como apostólica en los autores posteriores. La TN areopagítica, situada en este contexto histórico primitivo, tiene un sentido determinado muy diverso, como se ve, de la $T N$ conciliadora de contenido escatológico. En esta hipótesis el

129. Sobre esto cfr. Ammonio Sakkas I, pp. 88-89.

130. Cfr. DN 681A - 684D; Ammonio Sakkas I, pp. 384-389. Al final de esta exposición agradezco imo ex corde la parte que mi amigo, Prof. José Oroz Reta, ha tenido en la ređacción última de este trabajo. 
fraude del $C D$, como hemos visto, se sometió hacia el 500/520, introduciendo como teología cristiana un sistema espúreo.

El pseudonimato, en esta hipótesìs, supone en el $C D$ un sistema bastardo de origen emanatista, inspirado en Proclo. Es una corriente mítica y mistagógica en la que el hombre experimenta una corriente salvífica en ciclos generativos, cuya evolución parte de la realidad triádica primitiva por negaciones que se coronan con la elevación definitiva al Uno supremo, que es la afirmación. Este sistema de carácter ajeno al evangelio subsana gradualmente su ilegitimidad, primero en Máximo el Confesor, y después en la corriente escolástica, especialmente santo Tomás.

El carácter originariamente pagano y neoplatónico del $C D$ lo admiten en general los autores que identifican al Ps. Dionisio con un autor dependiente de Proclo. De ahí se seguiría que la corrección del $C D$ introducida por el IV Concilio de Letrán y por santo Tomás sería el origen de la Teología tradicional católica, y no la enseñanza auténtica de la Iglesia primitiva anterior al 300.

La gravedad de este resultado general de la teología afecta de un modo particular a la doble interpretación de la $T N$, es decir a la que se basa en la interpretación auténticamente cristiana del $C D$ y a la $T N$ cuyo punto de partida es el sistema doctrinal bastardo inspirado en Proclo y continuado por las corrientes reformadoras y filosóficas modernas. Prescindiendo del aspecto ortodoxo o heterodoxo de ambas corrientes de la $T N$, nos es preciso apreciarlos por el grado de conocimiento de Dios y de la intensidad de la vida divina que una y otra corriente pueden proporcionar al hombre. En la $T N$, auténticamente evangélica y primitiva, inspirada en la fe integral de la Iglesia apostólica, el conocimiento religioso y divinizador no está en proporción con la capacidad psicológica y consciente de los creyentes, que es sólo un pre-requisito del conocimiento divino y no un coeficiente causal de la asimilación cognoscitiva de la divinidad.

El conocimiento oscuro de la fe, unido a la caridad y a la esperanza junto con la participación de los sacramentos, eleva al alma a un grado de unión sobrenatural mística de la mente con Dios, cuya profundidad supera toda medida concreta y definida. Es una posesión participada de la divinidad en las diversas zonas cognoscitivas - sensible, racional intuitiva y sobrenatural de la visión-que no está limitada por fronteras de la consciencia psíquica, como ocurre en los fenómenos naturales místicos, mistagógicos y filosóficos, propios del libre examen y de las experiencias positivas, siempre limitadas, pasajeras y mudables de la conciencia psicológica, 
en la cual se desarrolla la $T N$ del sistema emanatista de Proclo, inspirador del supuesto fraude literario del $C D$ en el síglo $\mathrm{V}$.

El elemento diferenciador está en las relaciones interpersonales propias de la comunicación lingüistica que enriquece a los interlocutores. Son relaciones desconocidas e imposibles en un sistema emanatista. Es la diferencia radical entre los neoplatónicos paganos y el Areopagita. En la Escritura y en el $C D$ la Palabra de Dios, que da su individualidad inconfundible a cada ser, en los creados dotados de razón les comunica el poder de relacionarse y enriquecerse vitalmente aun con conocimientos que pueden ser inaccesibles al interlocutor que escucha. Ese enriquecimiento -imposible en la emanación fuera del radio de la conciencia psíquica- es el coeficiente propio de la fe natural que prestamos al interlocutor humano, y de la fe sobrenatural prestada a Dios al comunicarse por la revelación de los misterios, para nosotros inefables, nos da propiedades superiores infinitamente a las perfecciones de la naturaleza creada. Esta es la diferencia entre la teología de la inmanencia pura, propia de la emanación impersonal, y la trascendencia objetiva que desde el exterior se nos comunica en forma inmanente por medio de la fe y la visión de Dios sobrenatural.

\section{Eleuterio ELORDUY}

